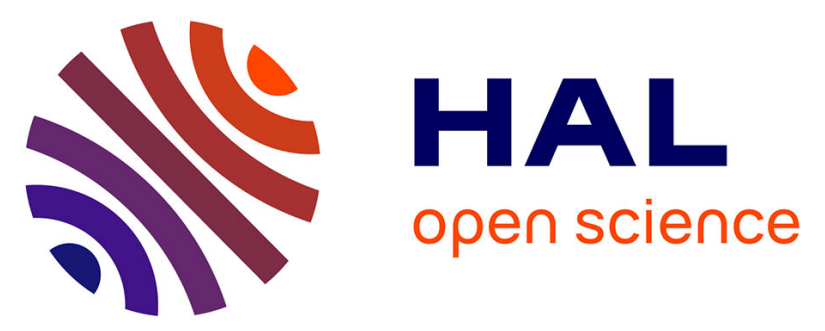

\title{
How many insects can a great tit population prey on in apple organic orchards? A modelling bioenergetics study
}

Michel Génard, Jean-Charles Bouvier, Thomas Delattre, Claire Lavigne, Francoise Lescourret, Jean-Francois Toubon, Thomas Boivin

\section{- To cite this version:}

Michel Génard, Jean-Charles Bouvier, Thomas Delattre, Claire Lavigne, Francoise Lescourret, et al.. How many insects can a great tit population prey on in apple organic orchards? A modelling bioenergetics study. Acta Horticulturae, 2017, 1160, pp.301-306. 10.17660/ActaHortic.2017.1160.43 . hal-01605994

\section{HAL Id: hal-01605994 \\ https://hal.science/hal-01605994}

Submitted on 26 May 2020

HAL is a multi-disciplinary open access archive for the deposit and dissemination of scientific research documents, whether they are published or not. The documents may come from teaching and research institutions in France or abroad, or from public or private research centers.
L'archive ouverte pluridisciplinaire HAL, est destinée au dépôt et à la diffusion de documents scientifiques de niveau recherche, publiés ou non, émanant des établissements d'enseignement et de recherche français ou étrangers, des laboratoires publics ou privés.

\section{다(1)(2)}

Distributed under a Creative Commons Attribution - ShareAlike| 4.0 International 


\title{
How many insects can a great tit population prey on in apple organic orchards? A modelling bioenergetics study
}

\author{
M. Génard ${ }^{1}$, J.C. Bouvier ${ }^{1}$, T. Delattre ${ }^{1}$, C. Lavigne ${ }^{1}$, F. Lescourret ${ }^{1}$, J.F. Toubon ${ }^{1}$ and T. Boivin ${ }^{2}$ \\ 1INRA, UR 1115 PSH, Domaine Saint Paul, Site Agroparc, 84000 Avignon, France ; 2INRA, UR629 URFM, Domaine \\ Saint Paul, Site Agroparc, 84000 Avignon, France.
}

\begin{abstract}
Orchards represent relevant study systems for investigating the functional role of insectivorous birds as regulators of pest insect populations. In this context, we used a bioenergetics model (Wiens and Innis, 1974) to estimate the seasonal variation in daily insect consumption by natural populations of the great tit (Parus major) in organic apple orchards. This model allowed us to estimate the changes in both adult densities and energy requirements in a $P$. major population, using field-measured parameters such as the brood size, and the length of incubation. The calculation of insect consumption rate by birds was based on both the existing literature on great tit diets and the simulated energy requirement of a great tit population. The effect of a temperature increase on energy requirement has been quantified. This study opens the way to consider the functional role of birds in agricultural landscapes and how this role may translate to ecosystem services.
\end{abstract}

Keywords: bird, Parus major, pest, arthropod, model, population dynamic, energy requirement

\section{INTRODUCTION}

The great tit (Parus major L.) is a common species in France that breeds readily in nest boxes, in particular in agro-ecosystems (Bouvier et al., 2005). The resulting significant increase in local bird density could lead to greater control of crop insect pest populations by birds. The codling moth (Cydia pomonella L.) is a major agricultural pest worldwide and the most serious pest in southern French apple orchards. Previous studies have investigated the efficiency of predation by birds, including tits (Parus spp.), on codling moth larvae in apple orchards worldwide, documenting predation levels reaching occasionally 90\% (Neff, 1942; Hagley, 1970; Solomon et al., 1976; Solomon and Glen, 1979; Stairs, 1985). However, a better understanding of the seasonal dynamics of such predator-prey relationships remains a key issue to evaluate the potential of great tit populations to negatively impact apple pest populations, and thus to contribute to apple crop protection. The bi-trophic relationship (great tit-codling moth) could help us in the management of the great tit population (e.g. using nest-boxes to increase the breeding population). In this context, we propose here to assess the link between the seasonal population dynamics of the great tit and the seasonal dynamics of its insect consumption in apple orchards, with a possible emphasis on codling moth consumption. Further, as energy requirements of birds depend on environmental temperature, it would also be important to assess the extent at which the future increasing temperature may affect insect consumption by great tits.

We used a bioenergetics model developed by Wiens and Innis (1974) and revised and documented by Rexstad (1982) in a double objective: (1) to estimate the seasonal variation in daily insect consumption by a great tit population in apple organic orchards, and (2) to analyze the effect of a $2^{\circ} \mathrm{C}$ increase of temperature on great tit energy requirement. This model has been previously employed to estimate the impact of several granivorous passerines on cereals and pine seeds (Wiens and Dyer 1975; Génard and Lescourret, 1987; Benkman et al., 2012) and to compare the energy requirements of different bird communities (Wiens and Nussbaum, 1975). 


\section{MATERIALS AND METHODS}

The study area was located in south-eastern France (Avignon region, $43^{\circ} 96^{\prime} \mathrm{N}, 4^{\circ} 82^{\prime} \mathrm{E}$ ), in a flat agricultural plain (40-60 $\mathrm{m}$ a.s.l.) characterized by a dense network of ditches and hedgerows, and a mixture of farming systems. The agricultural landscape is predominantly composed of fruit culture, and of vineyard, vegetable, and cereal crops to a lesser extent. Apple and pear orchards are the most common fruit cultures ( $87 \%$ of the fruit culture cover) in this area. Fieldwork was conducted on 4 commercial apple organic orchards (areas: 0.45 , $0.87,0.82$ and $0.80 \mathrm{ha}$ ) that were surrounded only by organic orchards. The minimum distance between two orchards approximated $2.5 \mathrm{~km}$. In each orchard, apple tree density was approx. 1500 trees ha-1 with an average tree age of about 30 years. Nest boxes were set in each of these 4 orchards at least $20 \mathrm{~m}$ from the orchard edge and separated by $30 \mathrm{~m}$ (i.e. 5 nest-boxes ha-1). Great tit breeding parameters (clutch size, date of incubation, hatching and fledge success) were monitored all along the 2001 spring and summer. Great tit density was estimated either by counting the birds in the orchards in winter (line transect method) or by counting the number of nest-boxes occupied by the great tits in spring. Codling moth population densities were estimated in several orchards of the study area by trapping diapausing larvae in autumn from 2011 to 2013. Traps were made of corrugated cardboard bands (width $10 \mathrm{~cm}$ ) wrapped around apple tree trunks approximately $15 \mathrm{~cm}$ above ground. Traps were set mid-July each year and collected in October.

The total daily energy demands of a great tit population was estimated from the computerized version of Wiens and Innis's (1974) bioenergetics model by Rexstad (1982) and Benkman et al. (2012). The model estimated daily densities of each age class (eggs, nestlings, fledglings, juveniles, and adults) in a population from user input of starting adult population size, vital rates, and the timings of molting and breeding. Following this populational process, the model calculated the expected daily energy demand in a population from seasonal temperature observations and estimates of mass- and life stagespecific metabolic rates based on existence energy requirement and seasonal costs of activity, reproduction and molting (Wiens and Innis, 1974). Model parameters were estimated from both data obtained in our study area and those available in the literature, e.g. egg, nestling, fledgling, juveniles and adults masses, length of time between development stages, and adult and juveniles death rates (Géroudet, 1984; Norte et al., 2010; Payevsky, 2006). Parameters related to the timing of breeding and the number of breeding attempts were estimated based on our observations of tits in the nest-boxes. Mean daily temperature data in 2001 were collected from the INRA meteorological station located within the study area (Avignon).

Simulation results have been converted into bird requirements in insects using data on passerine digestive efficiency (80\%), raw energy values of insects (5.3 $\mathrm{kcal} \mathrm{g}^{-1}$ dry mass), and both great tit temperature of thermos-neutrality and the proportion of insects in the great tit diet (100\% insects from March to October, and of $80 \%$ insects in winter) provided in literature (Castro et al., 1989; Velky et al., 2011; Crocker et al., 2002; Broggi et al., 2007). Such a requirement has been expressed as the daily fresh mass of insects consumed per adult.

\section{RESULTS AND DISCUSSION}

The daily energy consumption per non-breeding adult fluctuated highly due to the daily temperature variation (Figure 1a). Over a year, it shows a seasonal sinusoidal variation in the range of 22-34 kcal. The maximal and minimal energy consumption were in early April when the temperature is still low and bird activity is high (ca. Julian dates 100-120), and in early September when the temperature is still high and bird activity has decreased (ca. Julian dates 220-240), respectively.

Daily fresh mass of insects consumed per non-breeding adult increased until April and then decreased slowly until winter (Figure 1b). The daily fresh mass of insects consumed per non-breeding adult was estimated to $12-23 \mathrm{~g}$, which was of the same order of magnitude as the great tit mass $(17 \mathrm{~g})$. This result is consistent with similar measurements done on other bird species of the same mass (Crocker et al., 2002). Breeding activity (Julian dates 90- 
190) was associated with an increase in the daily fresh mass of insect consumed per breeding adult from 20 to $34 \mathrm{~g}$, which may reflect the specific costs of egg production and feeding of both nestlings and fledglings during this period. The total yearly insect consumption per non-breeding and breeding adult was about 6.1 and $6.7 \mathrm{~kg}$, respectively.


Figure 1. a) Simulated daily energy consumption per non-breeding great tit adult, and b) fresh mass of insects consumed per either breeding (dashed line) or nonbreeding adult (solid line).

Total estimated great tit density was very low in winter $\left(<100\right.$ individuals $\left.\mathrm{km}^{-2}\right)$. It then increased strongly in two phases due to nest-box colonization by breeding adults (in March, Julian dates 55-65) and to eggs laying (in April, Julian dates 90-120), reaching a maximum of 1200 individuals $\mathrm{km}^{-2}$ (Figure 2). There was a second maxima (800 individuals $\mathrm{km}^{-2}$ ) corresponding to a second brood in June. Population density decreased slowly until the end of October (Julian dates 290-300), after which most of the birds were assumed to emigrate from apple orchards.

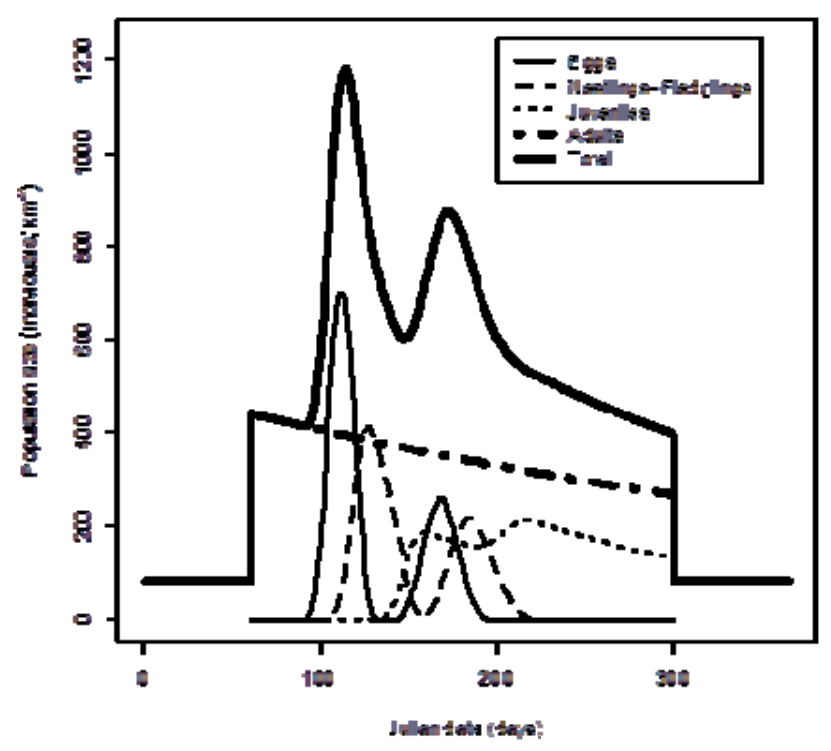

Figure 2. Estimated densities of different life stages of a great tit population (adults, eggs, nestlings, fledglings and juveniles) during a year time course. The total curve represents the sum of the densities of each life stage. 
From such estimated densities, we used the model to infer changes in individual energy requirements that could be converted into a daily fresh mass of insects consumed, on the basis of insect energy content. The model predicted a fairly low insect consumption in winter when great tits have a heterogeneous diet including both seeds and insects and when their densities in orchards are the lowest (Figure 3a). The model estimated the annual consumption of insects by a great tit population to $23.6 \mathrm{~kg}$ of fresh mass per hectare, to be compared to the $17 \mathrm{~kg}$ of invertebrates produced per hectare in temperate forest ecosystems (Gibb, 1960). In our estimations of the number of insects consumed by a great tit population in apple orchards, we considered insect mass to be either low (0.005 g dry mass) or high ( $0.1 \mathrm{~g}$ dry mass). Accordingly, the total number of insects consumed per year and per hectare ranged from 70000 to 1400000 (Figure 3b). The real number is probably closer to 1400 000 insect because great tit preys are fairly small. Indeed, Naef-Daenzer et al. (2000) have shown in forest ecosystem that great tits fed their young with caterpillars in the range of 0.006-0.015 g dry mass. This estimation is equal or superior to the Mols and Visser (2002) estimation of 73500 caterpillars ha-1 in apple orchard at the beginning of spring and to the maximal stock of Lepidoptera estimated in pine forest ecosystem (Gibb and Betts, 1963). In the hypothetical case in which great tits feed exclusively on codling moth larvae $(0.018 \mathrm{~g}$ dry

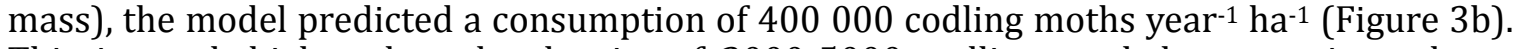
This is much higher than the density of 2000-5000 codling moth larvae estimated per hectare in our study area in autumn. The potential codling moth larvae consumption in winter was estimated to 25000 larvae which is again higher than the estimated field population density at this period. These results are in agreement with experimental studies on codling moth predation by birds (Solomon et al., 1976).
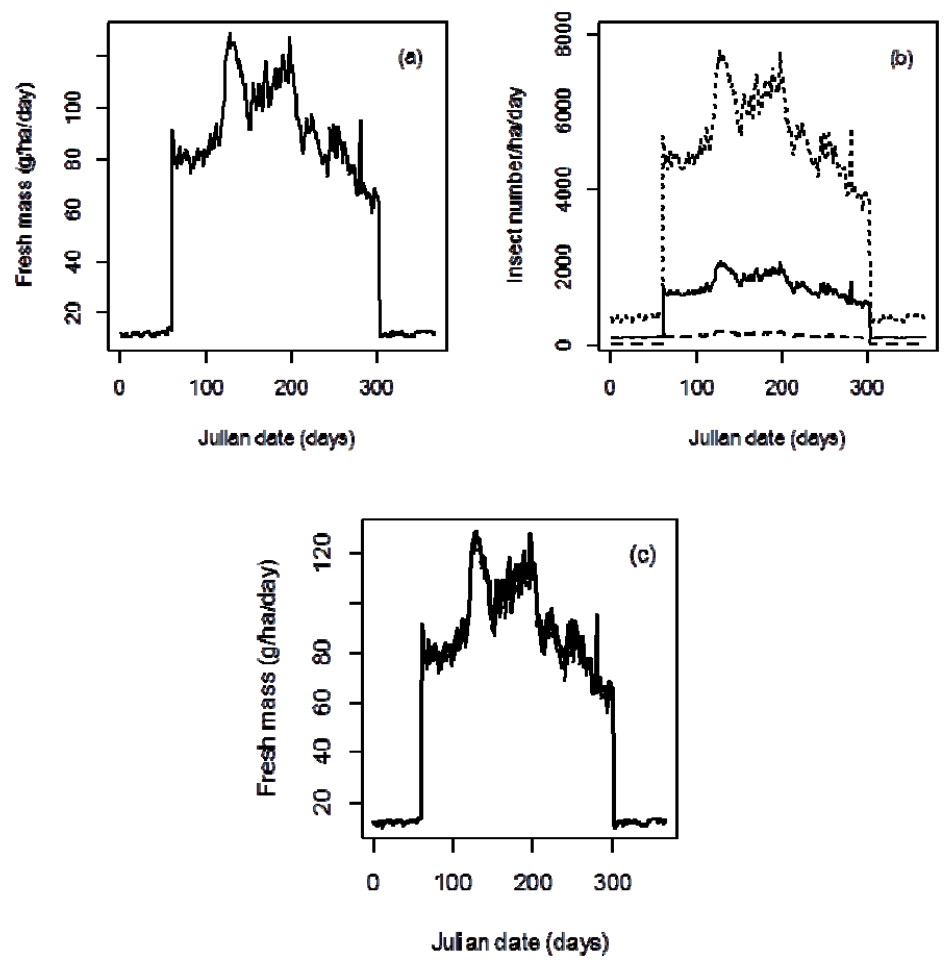

Figure 3. Estimated daily consumption of insects by the great tit population. a) Fresh mass consumed; b) number of insects consumed assuming different individual mass of insects: $0.005 \mathrm{~g}$ dry mass (dotted line), $0.1 \mathrm{~g}$ dry mass (dashed line) or mass of a codling moth larvae, $0.018 \mathrm{~g}$ dry mass (continuous line); c) Fresh mass consumed by the great tit population with the 2001 temperature (thick line) and in case of $2{ }^{\circ} \mathrm{C}$ increase of temperature (thin line). 
An important concern for the next decades is the global warming. The model has been used to evaluate the effect of a $2^{\circ} \mathrm{C}$ increase of temperature on insect consumption by a great tit population (Figure 3c). A temperature increase resulted in a decrease in energy consumption per adult, which led to a decrease in insect consumption of $4.3 \%$. However, the model overestimates probably that decrease of consumption because it does not consider the likely positive impact of the temperature on the population dynamic of the great tit.

\section{CONCLUSIONS}

This study focused on the functional role that the great tit may play in the regulation of insect populations in apple orchards. In most studies of bird-insect trophic interactions, birds significantly reduced the number of insect prey feeding on plants (Marquis and Whelan, 1994). Here we speculate that the great tit may contribute to the control of pest populations in orchards, including the codling moth, the most serious pest in southern French apple orchards. A sensitivity analysis is now required to identify the population and bio-energetic parameters that contribute the most to this possible regulation. Further investigation on foraging distances and on the diet of the great tit in orchards are also needed to improve the ability of the model to predict the consumption of pests.

To go further, the model has to consider the impact of the environment (e.g. climate, food supply, nest sites) on population dynamics parameters, including the effect of local migrations.

Agricultural systems such as orchard systems must do much more than simply deliver provisioning services (Lescourret et al., 2015). They must also provide regulating (which was the object of this study) and cultural (patrimonial biodiversity) services. Coupling the model of Wiens and Innis (1974) with a model of fruit production would open the way to consider multiple agro-ecosystem services in orchard systems.

\section{ACKNOWLEDGEMENTS}

We would like to thank the technical advisors and the orchard owners for facilitating field work, M. Talluto and C.W. Benkman for the R program of the bioenergetic model.

\section{Literature cited}

Benkman, C.W., Fetz, T., and Talluto, M.V. (2012). Variable resource availability when resource replenishment is constant: the coupling of predators and prey. Auk 129 (1), 115-123 http://dx.doi.org/10.1525/auk.2011.11069.

Bouvier, J.C., Toubon, J.F., Boivin, T., and Sauphanor, B. (2005). Effects of apple orchard management strategies on the great tit (Parus major) in southeastern France. Environ. Toxicol. Chem. 24 (11), 2846-2852 PubMed.

Broggi, J., Hohtola, E., Koivula, K., Orell, M., Thomson, R.L., and Nilsson, J.-Å. (2007). Sources of variation in winter basal metabolic rate in the great tit. Funct. Ecol. 21 (3), 528-533 http://dx.doi.org/10.1111/j.13652435.2007.01255.x.

Castro, G., Stoyan, N., and Myers, J.P. (1989). Assimilation efficiency in birds: A function of taxon or food type? Comp. Biochem. Physiol. 92 (3), 271-278 http://dx.doi.org/10.1016/0300-9629(89)90563-X.

Crocker, D., Hart, A., Gurney, J., and McCoy, C. (2002). Project PN0908: Methods for estimating daily food intake of wild birds and mammals. Final report (London: Central Science Laboratory, DEFRA).

Génard, M., and Lescourret, F. (1987). The Common Crossbill Loxia curvirostra in the Pyrenees: some observations on its habitats and on its relations with conifer seeds. Bird Study 34 (1), 52-63 http://dx.doi.org/10.1080/00063658709476936.

Géroudet, P. (1984). Les Passereaux d'Europe - Tome 2, De La Bouscarle Aux Bruants (Delachaux \& Niestlé).

Gibb, J.A. (1960). Populations of Tits and Goldcrests and their food supply in pine plantation. Ibis 102 (2), 163208 http://dx.doi.org/10.1111/j.1474-919X.1960.tb07112.x.

Gibb, J.A., and Betts, M.M. (1963). Food and food supply of nestling tits (Paridae) in Breckland pine. J. Anim. Ecol. 32 (3), 489-533 http://dx.doi.org/10.2307/2605.

Hagley, E.A.C. (1970). The distribution and survival of overwintering codling moth larvae in southern Ontario. Proc. Entomol. Soc. Ontario 100, 40-47.

Lescourret, F., Magda, D., Richard, G., Adam-Blondon, A.-F., Bardy, M., Baudry, J., Doussan, I., Dumont, B., Lefèvre, 
F., Litrico, I., et al. (2015). A social-ecological approach to managing multiple agro-ecosystem services. Curr. Opin. Environ. Sustain. 14, 68-75 http://dx.doi.org/10.1016/j.cosust.2015.04.001.

Marquis, R.J., and Whelan, C.J. (1994). Insectivorous birds increase growth of white oak through consumtion of leaf-chewing insects. Ecology 75 (7), 2007-2014 http://dx.doi.org/10.2307/1941605.

Mols, C.M.M., and Visser, M.E. (2002). Great tits can reduce caterpillar damage in apple orchards. J. Appl. Ecol. 39 (6), 888-899 http://dx.doi.org/10.1046/j.1365-2664.2002.00761.x.

Naef-Daenzer, L., Naef-Daenzer, B., and Nager, R.G. (2000). Prey selection and foraging performance of breeding Great Tits (Parus major) in relation to food availability. J. Avian Biol. 31 (2), 206-214 http://dx.doi.org/10.1034/j.1600-048X.2000.310212.x.

Neff, J.A. (1942). Comments on birds and codling moth control in the Ozarks. Wilson Bull. 54, 21-24.

Norte, A.C., Ramos, J.A., Sampaio, H.L., Sousa, J.P., and Sheldon, B.C. (2010). Physiological condition and breeding performance of the Great Tit. Condor 112 (1), 79-86 http://dx.doi.org/10.1525/cond.2010.080071.

Payevsky, V.A. (2006). Mortality rate and population density regulation in the Great Tit, Parus major L.: a review. Russ. J. Ecol. 37 (3), 180-187 http://dx.doi.org/10.1134/S1067413606030064.

Rexstad, E. 1982. Bird Model, version III. Description and documentation (Logan: Utah State University).

Solomon, M.E., and Glen, D.M. (1979). Prey density and rates of predation by tits (Parus spp.) on larvae of codling moth (Cydia pomonella) under bark. J. Appl. Ecol. 16 (1), 49-59 http://dx.doi.org/10.2307/2402727.

Solomon, M.E., Glen, D.M., Kendall, D.A., and Milsom, N.F. (1976). Predation of overwintering larvae of codling moth (Cydia pomonella L.) by birds. J. Appl. Ecol. 13 (2), 341-352 http://dx.doi.org/10.2307/2401784.

Stairs, G.R. (1985). Predation on overwintering codling moth populations by birds. Ornis Scand. 16 (4), 323-324 http://dx.doi.org/10.2307/3676698.

Velky, M., Kanuch, P., and Kristin, A. (2011). Food composition of wintering great tits (Parus major): habitat and seasonal aspects. Folia Zool. (Brno) 60, 228-236.

Wiens, J.A., and Dyer, M.I. (1975). Simulation modelling of Red-Winged Blackbird impact on grain crops. J. Appl. Ecol. 12 (1), 63-82 http://dx.doi.org/10.2307/2401718.

Wiens, J.A., and Innis, G.S. (1974). Estimation of energy flow in bird communities: A population bioenergetics model. Ecology 55 (4), 730-746 http://dx.doi.org/10.2307/1934410.

Wiens, J.A., and Nussbaum, R.A. (1975). Model estimation of energy flow in northwestern coniferous forest bird communities. Ecology 56 (3), 547-561 http://dx.doi.org/10.2307/1935490. 